\title{
CARTA ALEDITOR
}

\section{Victoria Astupiña Barrionuevo, mártir de la educación, a 50 años de su muerte}

\author{
Sebastián Legua Pérez ${ }^{1,2}$, Gina Munive Sivirichi ${ }^{1,2}$, Julio Taquiri González ${ }^{1,2}$ \\ Facultad de Medicina Humana, Universidad Nacional San Luis Gonzaga de Ica(1) \\ Sociedad Científica de Estudiantes de Medicina de Ica(2)
}

\section{Sr. Editor:}

La Universidad San Luis Gonzaga de Ica nace por la decisión heroica del pueblo Iqueño que por cabildo abierto el 18 de febrero de 1961 nombra una comisión que aprueba el "Acta de fundación de la universidad". En junio de 1962 se forma una asamblea "Pro creación" de la Escuela de Medicina Humana" formada por docentes y estudiantes, que obtienen asesoramiento para su creación, la cual que se inaugura el 18 de Mayo de 1963. Posteriormente la escuela cambio de nombre a Facultad de Medicina. Siendo esta la cuarta Facultad de Medicina creada en el país, luego de las facultades de Medicina de San Fernando(1856), de la Universidad Nacional de Trujillo(1958) y la Universidad San Agustín de Arequipa $(1958)^{1}$

Entre los años 1964 y 1966 en todo el país se firmaron una serie de convenios entre los Hospitales de salud y facultades de medicina. Nuestra facultad no fue ajena a esta situación y en 1965 firmó un acuerdo con el Ministerio de Salud para que el Hospital Regional se convierta en un Hospital Docente-Asistencial, esto causó la oposición de un grupo de Médicos que se sentían desplazados e incluso de parte de la población, que por desinformación llevó a la anulación de dicho acuerdo².

\footnotetext{
Una nueva lucha empieza por parte de los alumnos que en busca de soluciones resuelven realizar una "Marcha de Sacrificio Ica- Lima" para llevar su voz de protesta hasta el Congreso de la República. La fecha elegida para la marcha es el 20 de octubre de $1965^{3}$, ese día una delegación de estudiantes parte de la Plaza de Armas de Ica con la intención de llegar caminando a Lima para defender el futuro de la facultad de Medicina y hacer que el Hospital Regional de Ica sea docente.
}

Victoria Astupiña Barrionuevo fue hija única de Clementina Barrionuevo y Feliberto Miranda, enfermera de profesión, vivía en Lima pero su verdadera vocación la incentiva a dejar a su familia, amigos y trabajo para venir estudiar Medicina Humana a la ciudad de Ica. Fue miembro de la segunda promoción de la recién creada facultad y una comprometida estudiante, se identificó con la causa y llegó a formar parte de la "Comisión de Apoyo" que llevaría suministros para los estudiantes en la marcha. El fatídico 22 de octubre de 1965, la camioneta que llevaría estos suministros volcó en la carretera Panamericana Sur, provocando la muerte instantánea de la joven estudiante de 24 años por un traumatismo encéfalocraneano, dejando parapléjico al estudiante Víctor Luna Benavides y quedando heridos otros estudiantes que los acompañaban ${ }^{3}$.

Por eso, cada 22 de octubre, alumnos y docentes parten en peregrinación desde la facultad hacia "El Cambio", Subtanjalla, lugar del fatídico accidente. Para realizar aquí una romería y rendir homenaje a nuestra valiente dama. Luego de este penoso suceso, las promociones venideras tomaron la muerte de Victoria Astupiña como punto de quiebre para mejorar distintos aspectos en nuestra formación académica, científica y social.

Que el sacrificio y lucha de nuestras primeras promociones, la muerte de nuestra dama ícono, no haya sido en vano, es motivo por el cual debemos comprometernos tanto autoridades, docentes y alumnos en la defensa de nuestros derechos como estudiantes deuna Universidad pública, de poder educarnos en un campo clínico adecuado, que nos fue legado en la marcha de los mandiles blancos en defensa de nuestro Hospital docente.
A 50 años de la muerte de nuestra mártir de la educación,creemos conveniente hacer de conocimiento a toda la familia Danielina y la comunidad Iqueña que somos una facultad Ilena de historia, y es nuestro deber conocerla y enorgullecernos de ella.

Consideramos meritorio el reconocimiento a esta valerosa estudiante de medicina, y nos aunamos a la propuesta de nuestros compañeros en favor de gestionar y facilitar los trámites para que la Universidad Nacional San Luis Gonzaga de Ica le otorgue el título de Médico Cirujano.

\section{¿UNO NO AMA, LOQUE NO CONOCE!}

\section{REFERENCIAS BIBLIOGRÁFICAS}

1. Cabel Moscoso J. Universidad Nacional San Luis Gonzaga: La creación heroica de un Pueblo. García A., editor. Ica: San Marcos; 2000.

2. Loza Barrera P. El otro Médico. Ica: Pílades Loza Barrera editor; 2013.

3. Román Ruíz C. Historia de la Facultad de Medicina Humana de Ica. Ica: Carlos Román Ruíz; 2010. 